\title{
A Retrospective 15 year Review of a Single Centre Head and Neck Unit's Experience of Maxillectomy Surgery for Cancer
}

\author{
Paula Coyle ${ }^{1}$, David McAnerney², Rujuta Roplekar ${ }^{1}$, Kevin Chiu ${ }^{3}$, Tahir Mirza ${ }^{2}$, \\ Konstantinos Karavidas ${ }^{2}$, Andrew Dias ${ }^{1}$, Andrew Camilleri ${ }^{2}$, Chi-hwa Chan ${ }^{2}$, Prasad Kothari ${ }^{1}$ \\ 1. ENT Department , Luton and Dunstable University Hospital \\ 2. Maxillofacial Department, Luton and Dunstable University Hospital

\section{Introduction}

Oral or sinonasal cancer is a potential life changing diagnosis. Management of this condition may lead to facial disfigurement, while the associated loss of oral function can lead to nutritional deficiencies and difficulties when communicating with others leading to social isolation. Maxillary oral cancer is of particular concern due to the relatively benign symptoms leading to late presentation requiring extensive surgery

\section{Aim}

To perform a 15 year retrospective review of all patients that underwent maxillectomies at Luton and Dunstable Hospital. We aimed to review patient demographics, presentation and duration of symptoms, surgery/reconstruction, complications and follow up outcomes.

\section{Method}

Data was collected of all patients who underwent maxillectomies performed by the ENT and Oral and maxillofacial teams from years 2002 to 2017 inclusively. Patients notes were compiled from paper and electronic records by a multidisciplinary team of ENT, OMFS and Oncology. Data was collected and collated on Excel spreadsheets designed in accordance to other similar retrospective audits to allow direct comparison.

\section{Results}

70 maxillectomies were performed in the time period. 57 patients had notes available to review, although not all notes were complete.

\section{Demographics}

In our series of 57 patients, 33 were male and 24 female. The most common presenting symptoms were swelling (19) and pain (13), followed by incidental finding at routine hospital or dental follow up (10). 14 patients were current smokers, 16 ex-smokers. 29 patients drank alcohol.

$Y=$ number of Age at Diagnosis (years)

patients

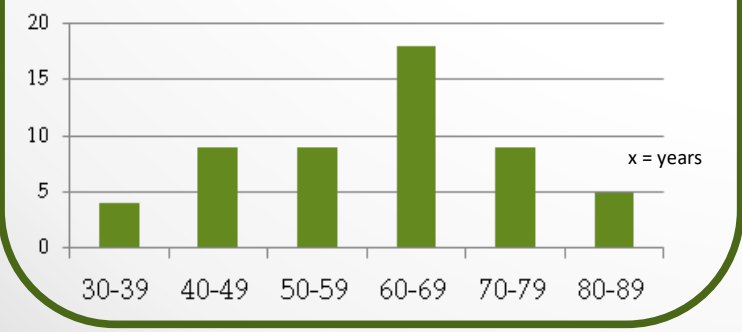

References

1 Lund VJ, Clarke PM, Swift AC, McGarry GW, Kerawala C, Darnell D. Nose and Paranasal sinus tumours: United Kingdom National Multidisciplinary Guidelines. J Laryngol Otol. 2016;130 (2): S111-S118.

2. Hayashi T, Nonaka S, Bandoh N, Kobayashi Y, Imada M, Harabuchi Y. Treatment outcome of maxillary sinus squamous cell carcinoma. Cancer. 2001 ; 92 (6) : 1495-1503

3. Joosten MHMa, de Bree R, Van Cann EM. Management of the clinically node negative neck in squamous cell carcinoma of the maxilla. Oral Oncol. $2017 ; 66$ : 87-92

4. Sangal NR, Lee YJ, Brady JS, Patel TD, Eloy JA, Baredes S, Park RCW. The role of elective neck dissection in the treatment of maxillary sinus squamous cell carcimona. Laryngoscope. 2017 Nov 29. (epub ahead of print)

\section{Staging and Histology}

$43(75 \%)$ patients had Stage 4 cancer on presentation, the next most common was stage 1 cancer with 3 patients. Neck nodes were positive in 12 patients.

Squamous cell carcinoma was the most common histological diagnosis, 40 patients. Followed by adenoid cystic, 6 , and adenocarcinoma, 3 .

\section{Operative Details}

33 partial maxillectomies and 24 total maxillectomies were performed.

28 patients had neck dissections, 9 orbital extension of their surgery, 5 skin resections and 3 had concurrent rhinectomy. Complications included 4 flap failures, 3 infections and 4 patients need to return to theatre.

Reconstruction was managed by obturators in 31 patients. 9 patients had radial forearm free flaps, 7 underwent fibular free flaps and other flaps included lat dorsi, rectus abdominus free flaps and temporalis flaps

30 patients had concurrent radiotherapy and 5 chemoradiation. 10 cases had local recurrence and 5 distant metastases. At time of the review 16 patients $(28 \%)$ were deceased and 41 patients in follow up.

\section{Discussion}

These cancers are rare and as expected our patient group saw a male predominance and age of presentation between the $5^{\text {th }}$ and $6^{\text {th }}$ decade $^{1}$. The majority were Stage 4 at presentation. SCC was the most common histological diagnosis.

Our survival rates for SCC is $67.5 \%$ (27 patients out of 40 ). However, our 5 year survival is $38.5 \%$ ( 5 patients out of 13 ) which is in keeping with the published five years overall survival for SCC $30-55 \% 1,2$. Our review has shown that we are providing a better reconstructive service to our patients over the latter five years of the study, but obturators are still a valid management option. 28 patients had neck dissections, 11 had positive neck nodes, 15 were NO and two unknown. However, 18 T4NO patients did not have a neck dissection. New evidence shows improved survival with elective neck dissections $s^{3,4}$. Our team will continue to develop and keep up to date.

Poor data recording could be explained by the trusts recent conversion of paper to electronic notes and patients returning to their local centres for follow up.

From this review we have shown the development of our own head and neck service while performing maxillectomies. We highlight how important retrospective studies are in reviewing not only current practices but most importantly patient outcomes.

\section{Outcomes}

\section{Conclusion}

